\section{Deslizamentos de sentido da palavra "mulher" em políticas públicas sobre violência doméstica}

Meaning displacements of the word "woman" in public policies on domestic violence

Matheus da Silva MEDEIROS (UNICAMP) medeirosmath@outlook.com

Michelle Gomes dos SANTOS (UNICAMP) michellegsantos5@gmail.com

Recebido em: 06 de dez. de 2019. Aceito em: 07 de abr. de 2020.
MEDEIROS, Matheus da Silva;

SANTOS, Michelle Gomes dos.

Deslizamentos de sentido da palavra

"mulher" em políticas públicas sobre violência doméstica. Entrepalavras,

Fortaleza, v. 10, n. 2, e1789, p. 1-18, maio-ago/2020. DOI: $10.22168 / 2237-$ 6321-21789.

Resumo: Neste artigo, à luz do referencial teórico da Análise do Discurso materialista, objetivamos analisar a cartilha "Mulher, vire a página...", publicada pelo Ministério Público do Estado de São Paulo, em 2016. A partir da emergência de políticas públicas voltadas para a violência doméstica em nossa sociedade, é relevante pensar sobre como essas políticas públicas produzem sentidos sobre violência de gênero e sobre como elas evidenciam um modo de funcionamento da ordem social. Nossa análise se detém nos deslizamentos da palavra "mulher", que ora ocupa o espaço de endereçamento, ora ocupa o espaço de discurso sobre. Além disso, mobilizamos o conceito de condições de produção (ORLANDI, 2010) para refletir sobre como formulações anteriores sobre violência doméstica são retomadas no discurso, e o de formações imaginárias, como proposto por Pêcheux (1997a), para pensar sobre a representação do lugar social da mulher na cartilha, partindo de um entendimento de que o gênero está inscrito no jogo das formações imaginárias e das relações de força materializadas na língua. Compreendemos que essas relações de força estão em constante transformação no motor da história, de modo que observamos deslizamentos de sentidos historicamente estabilizados sobre mulheres e violência doméstica.

Palavras-chave: Análise do discurso. Mulher. Violência doméstica. Deslizamentos de sentido. 
V. $10(2)$

1-18 maio-ago 2020

Abstract: In this paper, based on the theoretical and methodological framework of materialist Discourse Analysis, we aimed to analyze the guideline "Mulher, vire a página...", published by São Paulo State Prosecutor's Office, in 2016. Through the emergence of public policies on domestic violence in our society, it is relevant to study how these public policies produces meanings about gender-based violence and how they reveal a performance mode of social codes. Our analysis dwell on meaning displacements of the word "woman", which sometimes functions as addressing and sometimes as object of discourse; furthermore, we mobilize the concepts of conditions of discourse production (ORLANDI, 2010) to reflect on how former formulations about domestic violence are taken up in the discourse, and imaginary formation, as proposed by Pêcheux (1997a), to think about the representation of the social place of women in the guideline, based on our understanding of gender as inscribed in the movement of imaginary formation and in the balance of power materialized in language. We comprehend that this balance of power is constantly moving in the engine of history, so that we observed meaning displacements of historically stabilized senses about women and domestic violence.

Keywords: Discourse analysis. Woman. Domestic violence. Meaning displacements.

\section{Introdução}

Os casos de violência contra a mulher têm crescido muito nos últimos anos, apesar das políticas de conscientização das vítimas e de certo amparo oferecido por lei. Segundo o Ministério dos Direitos Humanos (MDH), entre janeiro e julho de 2018 a Central de Atendimento à Mulher registrou " 27 feminicídios, 51 homicídios, 547 tentativas de feminicídios e 118 tentativas de homicídios", chegando a 79.661 relatos de violência, dentre os quais 37.396 diziam respeito à violência física e 26.527 à violência psicológica (BRASIL, 2018, s.p). Mais recentemente, uma reportagem do site de notícias BBC Brasil apresentou um levantamento do Datafolha, realizado entre os anos de 2018 e 2019, que mostra que

1,6 milhão de mulheres foram espancadas ou sofreram tentativa de estrangulamento no Brasil, enquanto 22 milhões passaram por algum tipo de assédio, sendo que $42 \%$ dos casos de violência ocorreram no ambiente doméstico e apenas $52 \%$ das mulheres denunciou o agressor ou procurou por ajuda. (FRANCO, 2019, s./n.)

Com base nesses dados, podemos perceber que grande parte da violência contra a mulher acontece em âmbito familiar, caracterizando casos de violência doméstica. Essa violência pode vir de pessoas unidas por laços de parentesco civil, como o marido, padrasto, sogra; ou de laços de parentesco naturais, como por pai, mãe, avô ou irmãos (ALMEIDA, 2017, p. 19). Além disso, segundo Almeida (2017, p. 19), as práticas de violência são diversas, desde a violência psicológica, até agressão física e/ ou abuso sexual, estando a violência física e psíquica muitas vezes 
relacionadas; e, na falta da violência física, a violência psíquica pode se tornar algo difícil de ser identificado pela vítima (FARIA, 2006, p. 6).

É tendo em conta esse contexto de necessidade de enfrentamento ao crescente número de casos de violência doméstica contra a mulher que diversas organizações e governos de estados lançaram cartilhas de enfrentamento à violência doméstica, como a cartilha Vamos conversar?, da ONU Mulheres (2016), a Violência contra a Mulher: conheça, previna, combata, pelo APTAFURG Sindicato (Sindicato do Pessoal Técnico-Administrativo da FURG) (2016) e a Mulher, vire a página..., do Ministério Público do Estado de São Paulo (2016), analisada neste trabalho. Propomos, neste artigo, uma análise dos deslizamentos da palavra mulher na cartilha Mulher, vire a página..., ancorados no referencial teórico da Análise do Discurso desenvolvida por Michel Pêcheux (1997a, 1997b, 1999), na França, e por Eni Orlandi (2010), no Brasil.

Na medida em que se fazem necessárias políticas públicas voltadas para a violência doméstica contra a mulher, é relevante pensar sobre como essas políticas públicas produzem sentidos sobre violência de gênero, e sobre como elas evidenciam um modo de funcionamento da sociedade. Para além disso, colocamos as seguintes questões iniciais ao olharmos para nosso objeto de análise: para quem essas cartilhas se direcionam? Para as mulheres vítimas de violência doméstica? Que sentidos são produzidos sobre as mulheres? Essas questões iniciais nortearam o desenvolvimento da nossa análise sobre a $4^{\mathrm{a}}$ edição da cartilha Mulher, vire a página... (SÃO PAULO, 2016), em que observamos deslizamentos de sentido pelo uso da palavra mulher, que ora ocupa o espaço de endereçamento, ora ocupa um espaço de discurso sobre.

\section{O referencial teórico-analítico da Análise do Discurso}

Para o cumprimento dos nossos objetivos, é relevante ter em conta as condições de produção da cartilha Mulher, vire a página.... Como em Orlandi (2010), pensamos as condições de produção tanto em sentido amplo - o contexto sócio-histórico, ideológico que determina os dizeres e sentidos - quanto o contexto imediato, que envolve os sujeitos e instituições os quais, em nosso caso, se responsabilizam pela produção da cartilha. Como destacado pela autora, as formulações se encontram na confluência dos eixos da memória (os já-ditos que significam os dizeres) e da atualidade, de modo que todo dizer é histórico e significado pela exterioridade, inscrita no interior da textualidade pelo funcionamento do interdiscurso. 
V. $10(2)$

1-18 maio-ago 2020

O eixo da memória organiza os saberes e sentidos naturalizados, sedimentados enquanto memória discursiva e evidentes pelo efeito ideológico. Toda e qualquer formulação se produz no encontro da memória com a atualidade, por isso estabelece alguma relação com as repetições históricas. De acordo com Achard (s.d apud PÊCHEUX, 1999), os dizeres estão sempre sujeitos ao acontecimento, uma desregularização dos sentidos provenientes do eixo da memória. Dito de outro modo, um enunciado, produzido em uma determinada condição de produção, pode ser repetido, redefinido, contradito, reconfigurado ou desestabilizado, pois a memória discursiva

é constitutivamente afetada pelas falhas que atravessam a língua e as contradições que estruturam a história, o que se materializa no seu caráter necessariamente lacunar e equívoco. Memória, portanto, estruturada pelo esquecimento, que funciona por uma modalidade de repetição vertical, que é ao mesmo tempo ausente e presente na série de formulações: ausente porque ela funciona sob o modo do desconhecimento, de um não-sabido, não-reconhecido, que se desloca, e presente em seu efeito de retorno, de já-dito, de efeito de pré-construído, de recorrência das formulações, produzindo a estabilidade dos objetos do discurso. (ZOPPI-FONTANA; FERRARI, 2017, p. 11-12)

A cartilha dialoga com dizeres historicamente estabilizados referentes à mulher e à violência doméstica, dizeres que significam as relações de gênero em nossa sociedade e inscrevem-se no jogo das relações de força que determinam ideologicamente o discurso. Nesse sentido, ao mesmo tempo em que, no Brasil, por um lado, em "2010 se registravam 5 espancamentos a cada 2 minutos, em 2013 já se observava 1 feminicídio a cada 90 minutos e, em 2015, o serviço de denúncia Ligue 180 registrou 179 relatos de agressão por dia", nos tornando um dos 10 países com maiores taxas de feminicídio no mundo (ARTIGO 19, 2018, s.p); por outro, há o acontecimento histórico do Feminismo, que rompe com um círculo de repetição das condições das mulheres na sociedade (ZOPPI-FONTANA; FERRARI, 2017). Enquanto acontecimento, os movimentos feministas mobilizam uma agenda política de demandas e intervenções sociais, que emergem no discurso pela instauração de uma nova rede de sentidos, estabelecida por sujeitos que não se reconhecem nas formas tradicionais de representação e nos discursos historicamente estabilizados e consolidados na memória discursiva.

O deslocamento e repetição da historicidade de representações tradicionais femininas que projetam a figura da mulher como subalterna/ submissa encontram-se materializados no discurso, uma vez que, a 
partir de uma concepção materialista, o discurso é o lugar material da luta ideológica e das contradições que dividem sujeitos e sentidos. Há condições históricas, ideológicas e institucionais que determinam que os sentidos produzidos sobre mulheres sejam esses, e não outros; e os sujeitos são fundamentalmente constituídos por esquecimentos no que diz respeito aos seus dizeres. Conforme Orlandi (2010), na Análise do Discurso, não pensamos o sujeito como o centro e origem do dizer: o sujeito é dividido e contraditório, na medida em que é atravessado pela língua e pela história, afetado por elas.

As posições de onde ele enuncia não lhe são acessíveis, pois o sujeito não tem acesso direto à exterioridade. Segundo Pêcheux (1997b), é a ideologia quem produz a ilusão de que o sujeito é a origem do sentido e do dizer, e de que um dizer só poderia ser aquele, e não outro. Trata-se, logo, de um processo em que a ideologia dissimula o seu funcionamento na produção discursiva, o que leva o sujeito a desconhecer que é afetado pela memória e pelo "que pode e deve ser dito", as formações discursivas que os determinam a partir do lugar de onde eles enunciam (PÊCHEUX, 1997b, p. 160). Ainda assim, embora regido e administrado, o processo de significação é aberto: "sentidos e sujeitos escorregam, derivam para outros sentidos, para outras posições" (ORLANDI, 2010, p. 53). À deriva, o deslizamento e o equívoco são condições para a realização da linguagem, e possibilitam tanto a repetição quanto a emergência de brechas discursivas para a constituição de formas outras de subjetivação, descoladas dos discursos dominantes.

Os discursos sobre a problemática da violência doméstica são um dos locais privilegiados para observação das assimetrias e contradições sociais de gênero, materializados também na discursividade de uma política pública voltada para esta questão, tal como a cartilha Mulher, vire a página.... Entendemos que o gênero está inscrito no jogo das formações imaginárias, definidas por Pêcheux (1997a) como as representações dos lugares sociais ocupados pelos sujeitos ao falarem; isto é, trata-se de lugares que os interlocutores se atribuem no jogo discursivo, a partir das representações que cada um faz do próprio lugar social e do lugar social do sujeito com quem fala. Com base em Pêcheux (1997a), Orlandi (2010) afirma que as formações imaginárias funcionam a partir de mecanismos de antecipação, em que o sujeito se antecipa com relação aos sentidos que suas palavras produzem para dizê-las de acordo com o efeito que pensa produzir para seu interlocutor. Da 
V. $10(2)$

1-18

maio-ago

2020

mesma forma, "o lugar a partir do qual o sujeito fala é constitutivo do que ele diz" (ORLANDI, 2010, p. 39), de forma que as relações de forças e hierarquias sociais são projetadas nesse funcionamento da projeção, antecipação e representação do lugar do outro.

Mariana Cestari (2015), em sua tese de doutorado, realiza uma contribuição importante para esse quadro teórico ao defender que as formações imaginárias produzem uma força argumentativa. Ela analisa que corpos negros femininos, significados como sem voz e sem raciocínio em posições racistas, projetam do seu lugar enunciativo imagens de corpos consciente de si e da própria negritude, em busca da identidade negra e da liberdade de ser. A partir da perspectiva de que os sentidos são construídos por relações, que apontam tanto para dizeres futuros quanto para os discursos que os sustentam, buscamos apontar para o jogo de imagens na constituição de uma representação legítima e digna sobre a mulher na cartilha, que produz rupturas e deslizamentos com relação aos sentidos historicamente repetidos sobre a mulher. Entendemos, tal como Cestari (2015), que tal efeito é argumentativo, na medida em que reforçar uma determinada representação, e não outra, é um gesto político de tomada de posição, inseparável do quadro das relações desiguais de gênero.

\section{A materialidade discursiva da cartilha: contradição, apagamento e discurso sobre}

A cartilha Mulher, vire a página... foi publicada pelo Ministério Público do Estado de São Paulo, em 2016. Selecionamos para análise a quarta versão da cartilha, cuja primeira publicação aconteceu em 2011, inspirada na cartilha Mulher, Vire a Página do Ministério Público do Mato Grosso do Sul, e no manual Enfrentando a Violência Contra a Mulher: Orientações Práticas para Profissionais e Voluntários(as), publicado em 2005 pela Secretaria Especial de Políticas para as Mulheres. Sua primeira edição foi também a primeira ação desenvolvida pelo Grupo de Atuação Especial de Enfrentamento à Violência Doméstica (GEVID), e desde então a cartilha vem sendo revisada e ampliada, com ações voltadas à efetivação da Lei Maria da Penha e à prevenção de situações de violência (SÃO PAULO, 2016, p. 4-5). Esse aspecto é interessante de se destacar, pois mostra que a iniciativa de formulação da cartilha não é isolada, mas se inscreve em um conjunto amplo de medidas que visam 
ao combate à violência doméstica, como a aprovação de projetos de leis e o reconhecimento de condições político-ideológicas que produzem assimetrias sociais entre as próprias mulheres, não compreendidas enquanto grupo homogêneo. Um exemplo disso é a elaboração de uma versão dessa cartilha voltada para mulheres bolivianas que vivem no Estado de São Paulo ${ }^{1}$.

Em um primeiro momento, destacamos a importância de traçar algumas considerações sobre a materialidade desse objeto discursivo: a cartilha. Historicamente, a elaboração de cartilhas como forma de ensino ou vulgarização de um conhecimento remete a um método de alfabetização muito utilizado no século XX, no Brasil. Uma das principais críticas à cartilha como método de ensino vinha de seu distanciamento da realidade, já que elas não concentrariam situações do dia a dia dos alunos, mas textos descolados da realidade (COLLARES, 2015, p. 25299), além de terem a repetição como método de aprendizagem (SANTOS; SANTOS; MACEDO, 2012).

Quando nos debruçamos sobre a cartilha partindo do referencial teórico da Análise do Discurso, passamos a considerá-la um espaço político (portanto, contraditório) em que emergem sentidos em estreita relação com aqueles aos quais se opõe. Ou seja, a cartilha é um espaço de confronto: trata-se de um material atravessado por contradições, por posições ideológicas que concorrem em nossa formação social. No entanto, ela não se apresenta dessa forma: como objeto discursivo que busca difundir certas informações e conhecimentos, a cartilha predominantemente reproduz uma modalidade que Mariani (1996) chamou de discurso sobre. Em estudo sobre o funcionamento do discurso jornalístico-político sobre o Partido Comunista Brasileiro (PCB) desde sua fundação até 1989, Mariani (1996) considera o discurso jornalístico como uma modalidade de tal discurso. Segundo a autora (MARIANI, 1996, p. 64),

um efeito imediato do falar sobre é tornar objeto aquilo sobre o que se fala. Por esse viés, o sujeito enunciador produz um efeito de distanciamento - o jornalista projeta a imagem de um observador imparcial - e marca uma diferença com relação ao que é falado, podendo, desta forma, formular juízos de valor, emitir opiniões etc., justamente porque não se 'envolveu' com a questão.

${ }_{1}$ Tal cartilha pode ser acessada na página oficial do Ministério Público do Estado de São Paulo. Disponível em: <http://www.mpsp.mp.br/portal/page/portal/Cartilhas/ vuelta_la_pagina.pdf>. Acesso em: 01 mai 2020. 
V. $10(2)$

1-18 maio-ago 2020

Para a autora, o discurso sobre é uma modalidade de institucionalização dos sentidos, que se projeta como lugar de autoridade para transmissão de conhecimentos. O discurso sobre se apresenta como imparcial, devido ao apagamento da interpretação, por isso mesmo se apresenta como isento de subjetividade, como se apresentasse os fatos como eles são.

Como já adiantamos no início deste trabalho, em nosso objeto de análise, há uma oscilação entre falar com a mulher e falar sobre a mulher no decorrer da cartilha, e esses diferentes modos de enunciar produzem diferentes efeitos sobre a constituição de uma imagem da mulher vítima de violência doméstica. Entendemos que esse é o ponto de encontro entre o discurso sobre e as formações imaginárias, na medida em que, em alguns momentos, a cartilha abrirá mão do distanciamento da modalidade discurso sobre para falar diretamente com a mulher, e nesse movimento, percorrerá outro caminho de constituição de uma representação feminina. Há contradição, que como veremos, faz-se presente para resguardar a dignidade da mulher.

A contradição, como afirma Pêcheux (1997b), é inerente a qualquer formação social constituída sob a forma da luta de classes. Em razão disso, atravessa também o Ministério Público do Estado de São Paulo como agente da publicação e instituição pública. No Art. 127 da Constituição brasileira de 1989, o Ministério Público é definido como "instituição permanente, essencial à função jurisdicional do Estado incumbindo-lhe a defesa da ordem jurídica, do regime democrático e dos interesses sociais e individuais indisponíveis" (BRASIL, 1988, p.90). Percebemos nessa definição um apagamento do político, o que é característico do texto jurídico: da perspectiva em que nos inscrevemos, não existe consenso, mas disputa nos interesses sociais, e tampouco as diversas posições ideológicas em concorrência estarão sempre alinhadas à "defesa da ordem jurídica", estabelecida como pilar do Estado brasileiro. Dessa forma, o Ministério Público é um órgão cuja atuação se dá no centro de relações de força, e cujo caráter contraditório é silenciado na direção de uma projeção imaginária como instituição não-ideológica, o que tem efeitos sobre o discurso da cartilha. 


\section{Deslizamentos da palavra "mulher" na cartilha "Mulher, vire a página..."}

Logo no início da cartilha, em sua apresentação, são colocados para o leitor os objetivos de informar sobre as principais formas de violência doméstica contra a mulher, bem como de orientar sobre como agir e denunciar nesses casos, de modo que as mulheres conheçam e acessem seus direitos. Ou seja, apesar de haver desde 2006 uma lei federal que estabeleça punições para casos de violência doméstica contra a mulher, a elaboração da cartilha parte pressuposto de que apenas a existência da lei como medida de combate e proteção é insuficiente: é preciso questionar os pilares que sustentam as relações desiguais de gênero e que permitem que a violência contra a mulher se perpetue. A cartilha se coloca, assim, como lugar de informação e conhecimento voltado às mulheres, no que se refere aos seus direitos em casos de violência doméstica.

Sobre a aplicação da Lei Maria da Penha,

é importante lembrar que [essa lei] se aplica às relações entre homens e mulheres e também às relações homoafetivas entre mulheres. Contudo, você perceberá que o texto da cartilha foi escrito como se o autor da violência fosse sempre um homem, isto porque, a maioria dos casos de violência doméstica e familiar contra as mulheres é praticada por homens, o que torna necessária a consolidação de ações e estratégias que deem visibilidade a esta forma de violência para erradicá-la. (SÃO PAULO, 2016, s./n.)

No parágrafo, há dois pontos importantes para a nossa análise: (1) ao dizer que a maioria dos casos de violência doméstica e familiar é praticada por homens, a questão da violência contra a mulher é inserida no contexto maior das relações desiguais de gênero, das contradições e assimetrias que constituem as relações entre homens e mulheres em nossa sociedade, em nosso tempo. Essa forma de abordar e tratar a questão da violência doméstica pode ser observada até o fim da cartilha, de modo que podemos fazer algumas considerações sobre a discursividade desse documento e como ela se inscreve na língua e na história. A partir de uma formação discursiva que compreende as relações de gênero como desiguais e a sociedade como machista, a cartilha se preocupa com os variados motivos que levam mulheres a não denunciar a violência sofrida por familiares e parceiros, assim como informa a sociedade de que a mulher que não denuncia não o deixa de fazer por desejar continuar na situação em que está, mas por medo, desamparo ou ter sido prometida de que o episódio violento não aconteceria novamente. Esse já é um deslocamento de representações 
V. $10(2)$

1-18 maio-ago 2020

historicamente consolidadas sobre a mulher vítima de violência doméstica, não mais significada como alguém que sente prazer diante da violência masculina, como reproduzido em ditados populares como "é mulher de malandro, gosta de apanhar".

Isso enfatizado, o segundo ponto é que, (2) ao colocar a necessidade de ações e estratégias que deem visibilidade para casos em que a violência doméstica contra a mulher é praticada por homens, a cartilha delimita também para qual(is) situação(ões) de violência ela se dirige - e não é a violência doméstica praticada em um relacionamento homoafetivo entre mulheres - . Dessa forma, as figuras e imagens na cartilha sempre representam um relacionamento heterossexual, entre uma mulher e um homem, em que este a violenta. Nesse contexto, recuperam-se redes de sentidos sobre as condições da mulher na sociedade, que significam as relações heterossexuais: falar sobre um relacionamento entre um homem e uma mulher implica falar sobre violência de gênero.

Dando início à nossa análise, analisaremos as primeiras sequências discursivas (SD). Para Courtine (2016, p. 20), um conjunto de sequências discursivas constitui o corpus discursivo e, segundo o autor, essas sequências remetem a um mesmo campo discursivo, sendo dominadas "por um determinado estado, suficientemente homogêneo e estável, das condições de produção do discurso".

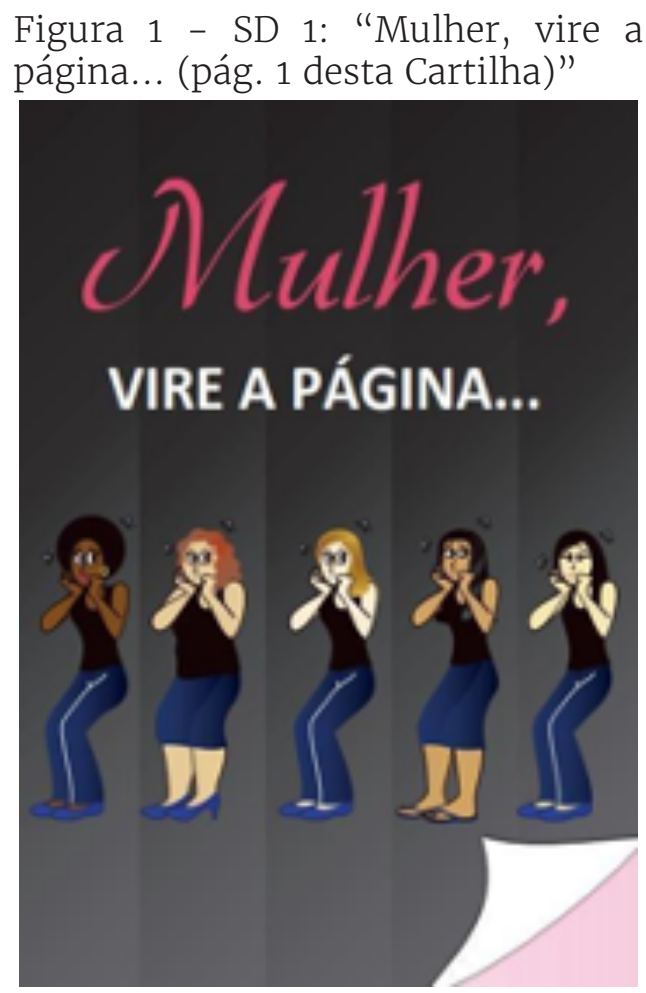

Fonte: São Paulo (2016). 
Figura 2 - SD 2: "Mulher, vire a página... (pág. 3 desta Cartilha)"

\section{...E SEJA PROTAGONISTA DE UM FINAL. FELIZ!}

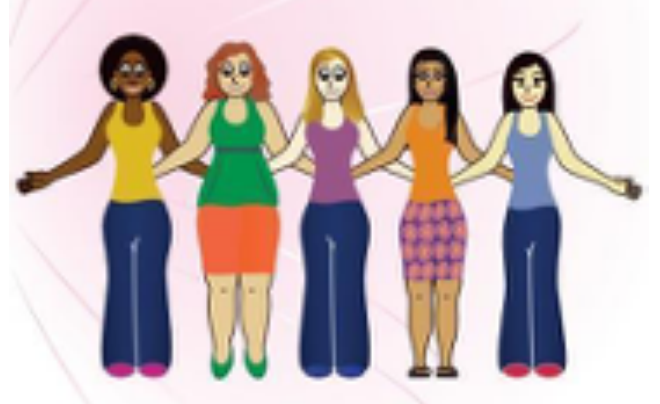

Fonte: São Paulo (2016).

Na SD 1, temos a palavra "mulher" colocada como o vocativo do enunciado: fala-se com a mulher - que é a mulher que se encontra em uma relação de violência doméstica/familiar - e dirige-se a ela, de modo que podemos compreender que a palavra "mulher" na SD 1 ocupa o espaço de endereçamento. Pelo processo metalinguístico do "vire a página", pede-se para que ela, além de seguir a leitura das orientações da cartilha, vire também a página de um relacionamento abusivo e violento. A atmosfera desse relacionamento com o agressor é materializada na página de capa da cartilha com a cor preta - é a única página com essa cor em toda a cartilha - e pelas imagens de diversas mulheres, uma ao lado da outra, com as mãos ao rosto e a expressão de amedrontamento e desamparo.

A borda inferior direita da página simula um efeito de que a página de capa da cartilha já está no processo de ser virada, mostrando que a próxima página tem a cor rosa. Na terceira página, também rosa, lê-se a SD 2: "... e seja protagonista de um final feliz". A cor rosa simbolizaria um novo momento na vida da mulher que virou a página da relação abusiva, que é caracterizada pela palavra "feliz" na SD 2. Além disso, a palavra "protagonismo" projeta uma imagem-mulher que diz respeito sobre sua vida e sobre como ela intervém no mundo: a mulher é protagonista de sua história, e essa história pode ser uma história com 
V. $10(2)$

1-18

maio-ago

2020

final feliz. Ao colocar a mulher nesse lugar de protagonista, ressaltase sua capacidade de agência e, portanto, decidir deixar para trás o que acredita que não lhe serve mais. Essa imagem projetada sobre a mulher é retomada em outros enunciados da cartilha e produzem sentidos de uma mulher emancipada, disposta a deixar para trás os rumos violentos de uma relação abusiva.

Notamos que há um deslizamento da palavra "mulher" como aquela que ocupa um espaço de endereçamento, como pode ser verificado na SD a seguir:

SD 3: "Por que as mulheres aguentam tanto tempo a violência doméstica? (pág. 6 desta Cartilha)"

Na SD 3, a pergunta que intitula a seção da cartilha parece não mais falar com as mulheres, mas preocupa-se em falar sobre elas ao listar os motivos pelos quais algumas mulheres não denunciam a violência doméstica sofrida. A palavra "mulher", então, desliza do seu espaço de endereçamento.

Identificamos aqui a modalidade do discurso sobre, que produz distanciamento do objeto sobre o qual se fala para projetar um lugar de autoridade, a fim de se transmitir conhecimentos. Isso fica explícito pelo fato de as respostas para a pergunta realizada na SD 3 serem mostradas logo em seguida, explicando situações como medo, vergonha ou pressão social dos familiares para que a mulher mantenha o relacionamento abusivo. Esse é um momento em que a cartilha atua sobre imaginários sociais ao representar a mulher, ao mesmo tempo se projetando a partir de um imaginário de autoridade/conhecimento. Esse discurso sobre a mulher, que se propõe didático e se faz passar como não-ideológico, propõe desmistificar a ideia de que a mulher continua em uma relação abusiva "porque gosta de apanhar", de modo que antecipa leituras possíveis sobre a situação da mulher que é vítima de violência doméstica; configura, portanto, uma questão de formação imaginária. A partir de um lugar de autoridade, a cartilha movimenta sentidos sobre mulheres, sentidos estes historicamente sedimentados como memória discursiva.

Ao retomar, atualizar e movimentar sentidos produzidos sobre mulheres vítimas de violência doméstica, a cartilha se inscreve no jogo das formações imaginárias, buscando transformar a visão da 
mulher passiva/complacente com as agressões. Esse jogo, como lembra Cestari (2015), é argumentativo. Para transformar a historicidade da representação das mulheres vítimas de violência doméstica como complacentes - o que, no funcionamento do discurso machista, autoriza a continuação das agressões - , a cartilha significa a mulher como emancipada e "protagonista" da sua vida, disposta a virar a página e a colocar um ponto final no relacionamento. Isso tem como efeito uma responsabilização da mulher para acabar com a violência, como podemos observar nas SD 4 e 5:

SD 4: "Romper uma relação violenta é um processo: cada mulher tem seu tempo. (pág. 6 desta Cartilha)"

Figura 3 - SD 5: "A violência vai se reproduzindo de geração para geração. A violência não se rompe sozinha. Busque apoio em um Serviço da Rede de Atendimento às Mulheres (pág. 22 desta Cartilha)"

A violência se reproduz de geração em geração...

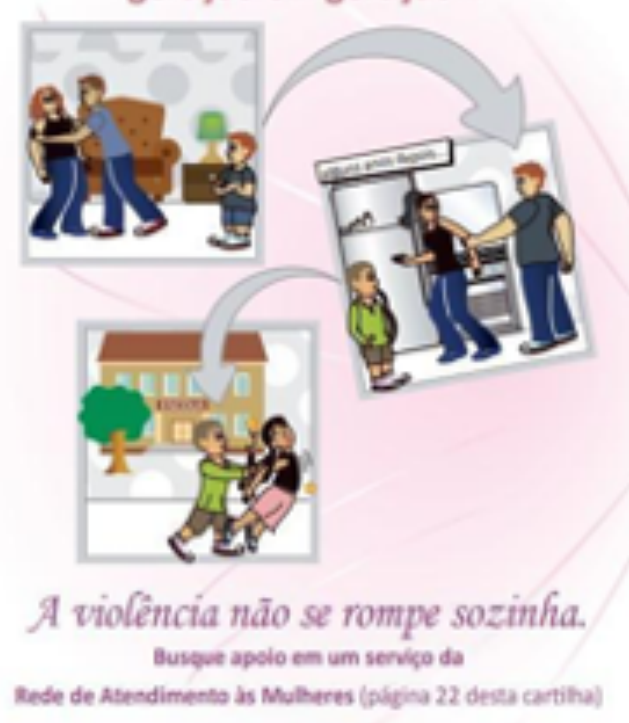

Fonte: São Paulo (2016).

Na SD 4, é importante observar o funcionamento do pronome possessivo "seu", que responsabiliza a mulher por acabar com a violência. É a mulher que precisa do tempo para romper com a relação violenta, cabendo a ela colocar um ponto final na relação tão logo esteja pronta 
V. $10(2)$

1-18

maio-ago

2020

para isso. Na SD 5, a cartilha apresenta uma sequência de imagens, mostrando como a violência no ambiente familiar é reproduzida pelos filhos em seu cotidiano. A construção discursiva da cartilha direciona para o sentido de responsabilização da mulher por interromper o abuso e o ciclo de violência. A frase "a violência não se rompe sozinha" também está alinhada a essa responsabilização da mulher, pois ao ressaltar que a violência não se rompe sozinha, a cartilha projeta a imagem de que é preciso que alguém rompa com a violência para que sua reprodução de geração para geração conheça um fim. Embora não diga explicitamente que quem deve fazer isso é a mulher, temos na SD 4 o funcionamento do pronome possessivo que aponta a mulher como aquela quem deve finalizar a relação.

Esse movimento se alia à produção de sentidos sobre uma mulher emancipada e dona de si nas SD anteriores, constantemente repetidos na cartilha. A repetição, que, vale lembrar, era utilizada como método de aprendizagem nas primeiras cartilhas de alfabetização, é observada em passagens que buscam lembrar a vítima de que ela não está sozinha e que existe uma rede de apoio para casos de violência, como na SD 5 e também nas seguintes sequências:

SD 6: "Você encontrará, nesta cartilha, [...] as medidas de proteção asseguradas pela Lei e os endereços dos serviços que compõem a Rede de Atendimento".

SD 7: "Existem profissionais que podem ajudá-la a romper o ciclo de violência! NÃO FIQUE SOZINHA!"

Os sentidos repetidos pela cartilha se contrapõem a um discurso historicamente construído que reserva à mulher um lugar de silêncio e submissão diante da violência. Pela repetição da ideia de que a mulher tem autonomia e responsabilidade de denunciar, a cartilha busca instaurar uma ordem discursiva que desloca os já-ditos que sustentam a desigualdade de gênero.

Em "Você encontrará", "podem ajudá-la a romper" e "NÃO FIQUE SOZINHA", não se fala sobre a mulher, mas com ela: esse espaço de endereçamento se configura como uma forma pela qual a cartilha convoca a mulher para se responsabilizar pela tomada de ação. Esse discurso irrompe em oposição a uma rede de dizeres anteriores que culpabilizam as mulheres pela violência sofrida, subvertendo discursos que as colocam como incapazes 
de reagir (SCARDUELI; MALISKA, 2013) e como sujeitos que compactuam com a violência sofrida. Nessa esteira de pensamento, de forma a não reforçar a ideia de que a mulher deve também ser responsabilizada quando não denuncia - uma vez que ela seria a responsável pela tomada de ação —, vimos na SD 3 que a cartilha informa que "cada mulher tem seu tempo", já falando sobre a mulher, e não com ela.

Dessa maneira, observamos que o espaço de endereçamento é mobilizado para responsabilizar e chamar a mulher para a ação da denúncia, movimento em que se projeta imagens de uma mulher autônoma e protagonista; enquanto o discurso sobre se utiliza para a conscientização de uma conjuntura social, familiar e individual que pode levar a mulher a não romper com o ciclo de agressões. $O$ jogo de imagens é também argumentativo, na medida em que impõe contrapontos: a mulher é emancipada, protagonista e responsável pela ação da denúncia, mas em caso de não realização da denúncia, não deve ser responsabilizada. Essa contradição é operada no discurso da cartilha para se ter um efeito duplo de oposição ideológica às posições machistas: por um lado, incentiva a mulher vítima de violência doméstica a denunciar; e por outro, opõe-se aos conhecidos discursos de que a mulher, quando não denuncia, é porque "gosta de apanhar".

\section{Considerações finais}

Neste artigo, buscamos analisar a construção discursiva de uma política pública voltada para a problemática da violência doméstica, a cartilha Mulher, vire a página..., publicada pelo Ministério Público do Estado de São Paulo. Observamos nesse material uma passagem entre falar para mulheres e falar sobre as mulheres, em que a palavra "mulher" ora ocupa o lugar de endereçamento, ora é o objeto sobre o qual se fala.

Isso pôde ser verificado em nosso corpus de análise, como na SD 1 ("Mulher, vire a página..."), em que o sujeito enunciador da cartilha explicitamente se dirige a uma mulher que é vítima de violência doméstica. Por outro lado, na SD 3 ("Por que as mulheres aguentam tanto tempo a violência doméstica?"), já não se fala com a mulher, mas sobre ela, com o objetivo de conscientizar os leitores para que não a culpem pela agressão sofrida.

No material, pode ser observado ainda um deslizamento da mulher como aquela que ocupa a posição de vítima para a responsável/ responsabilizada por acabar com uma situação de violência. Esse 
V. $10(2)$

1-18 maio-ago 2020

deslizamento encontra-se materializado linguisticamente na utilização de substantivos como "protagonismo" e na utilização do pronome possessivo "seu" na SD 4 ("Romper uma relação violenta é um processo: cada mulher tem seu tempo"); da mesma forma, a cartilha se inscreve no jogo das formações imaginárias ao representar a mulher de forma oposta aos discursos de complacência com a agressão que são correntes no senso comum, respondendo a esses discursos, presentes na materialidade da cartilha enquanto memória. Entendemos, portanto, que apesar de por vezes se constituir como discurso sobre e se distanciar da mulher ao colocála como objeto do discurso, a cartilha formula juízos sobre as mulheres e interage com os discursos outros sobre violência doméstica, discursos estes que são retomados/desestabilizados no processo discursivo de se propor uma representação emancipada da mulher.

Agradecimentos: Este trabalho é resultado das enriquecedoras discussões realizadas no curso "Gênero e Políticas Públicas: Uma abordagem pela Análise do Discurso", oferecido pela UNICAMP, no segundo semestre de 2019. Agradecemos, por isso, às professoras Laís Virgínia Alves Medeiros e Raquel Noronha Siqueira pelas recomendações e pelo incentivo à publicação, que fortalece nossos laços enquanto pesquisadores.

\section{Referências Bibliográficas}

ALMEIDA, M. I. G. Fatores associados à qualidade do sono e qualidade de via em mulheres sobreviventes de violência doméstica. 2017. Tese (Doutorado em Ciências da Saúde) - Faculdade de Enfermagem, Universidade Estadual de Campinas, Campinas, 2017. Disponível em: http://www.repositorio.unicamp. br/handle/REPOSIP/332902. Acesso em: jun. 2019.

APTAFURG SINDICATO. Violência contra a mulher: conheça, previna e combata. Rio Grande: Pluscom Editora, 35p., set-dez, 2016. Disponível em: http://www.aptafurg.org.br/novo_site/images/documentos/cartilha.pdf. Acesso em: jun. 2019.

ARTIGO 19. Dados sobre feminicídio no Brasil. 2018. Disponível em: https://artigo19.org/wp-content/blogs.dir/24/files/2018/03/Dados-SobreFeminic\%C3\%ADdio-no-Brasil-.pdf. Acesso em: abr. 2020.

BRASIL. Constituição (1988). Constituição: República Federativa do Brasil. Brasília - DF: Senado Federal, Centro Gráfico, 1998.

BRASIL. Governo Federal. MDH divulga dados sobre feminicídio. 2018. Disponível em: https://www.gov.br/mdh/pt-br/assuntos/noticias/2018/agosto/ligue180-recebe-e-encaminha-denuncias-de-violencia-contra-as-mulheres. Acesso em: abr. 2020. 
CESTARI, M. J. Vozes-mulheres negras ou feministas e antirracistas graças às Yabás. 2015. Tese (Doutorado em Linguística) - Instituto de Estudos da Linguagem, Universidade Estadual de Campinas, Campinas, 2015. Disponível em: http://www.repositorio.unicamp.br/handle/REPOSIP/271056. Acesso em: jun. 2019.

COLLARES. S. A. O. Origem da Cartilha no Brasil como instrumento privilegiado de controle do Estado. In: EDUCERE - CONGRESSO NACIONAL DE EDUCAÇÃO, 12., 2015, Curitiba. Anais eletrônicos, Curitiba: Editora Universitária Champagnat, 2015. Disponível em: https://educere.bruc.com.br/arquivo/ pdf2015/17575_7459.pdf. Acesso em: abr. 2020.

COURTINE, J. J. Definição de orientações teóricas e construção de procedimentos em Análise do Discurso. Tradução de Flávia Clemente de Souza e Márcio Lázaro Almeida da Silva. Policromias - Revista de Estudos do Discurso, Imagem e Som (LABEDIS/UFRJ), 1. ed., V.1, p. 14-35, Rio de Janeiro, jun. 2016. Disponível em: https://revistas.ufrj.br/index.php/policromias/article/view/4090/3058. Acesso em: jul. 2020.

FARIA, C. Estudo do aspecto odonto-legal das lesões corporais decorrentes de violência doméstica. 2006. Dissertação (Mestrado em Odontologia Legal e Deontologia) - Faculdade de Odontologia, Universidade Estadual de Campinas, Piracicaba, 2006. Disponível em: http://www.repositorio.unicamp.br/handle/ REPOSIP/289883. Acesso em: jun. 2019.

FRANCO, L. Violência contra a mulher: novos dados mostram que 'não há lugar seguro no Brasil'. BBC Brasil. 2019. Disponível em: https://www.bbc. com/portuguese/brasil-47365503. Acesso em: jun. 2019.

MARIANI, B. S. C. O comunismo imaginário: práticas discursivas da imprensa sobre o PCB (1922-1989). 1996. Tese (Doutorado em Linguística) - Instituto de Estudos da Linguagem, Universidade Estadual de Campinas, Campinas, 1996. . Disponível em: http://www.repositorio.unicamp.br/handle/ REPOSIP/270690. Acesso em: 21 jun. 2019.

ONU MULHERES. Vamos conversar? Cartilha de enfrentamento da violência doméstica e familiar contra as mulheres. Brasília-DF, 2016. Disponível em: http://www.onumulheres.org.br/wp-content/uploads/2016/04/CARTILHA DF.pdf. Acesso em: jun. 2019.

ORLANDI, E. P. Análise de discurso: princípios \& procedimentos. Campinas, SP: Pontes, 2010.

PÊCHEUX, M. Análise automática do discurso (AAAD-69). In: GADET, F.; HAK, T. (Orgs.). Por uma análise automática do discurso: uma introdução à obra de Michel Pêcheux. Tradução de Bethania S. Mariani et al. 3. ed. Campinas, SP: Editora da Unicamp, 1997a.

PÊCHEUX, M. Papel da memória. In: ACHARD, P. et al. (Org.). Papel da memória. Tradução e introdução de José Horta Nunes. Campinas: Pontes, 1999.

PÊCHEUX, M. Semântica e discurso: uma crítica à afirmação do óbvio. Tradução de Eni Puccinelli Orlandi et al. 3. ed. Campinas, SP: Editora da Unicamp, $1997 \mathrm{~b}$.

SANTOS, E. D.; SANTOS, M. G. A.; MACEDO, V. S. O método das cartilhas. In: COLÓQUIO INTERNACIONAL "EDUCAÇÃO E CONTEMPORANEIDADE", 6., 2012, 
V. $10(2)$ 1-18 maio-ago 2020

São Cristóvão. Anais eletrônicos, São Cristóvão: EDUCON, 2012. Disponível em: http://educonse.com.br/2012/eixo_12/PDF/23.pdf. Acesso em: abr. 2020.

SÃO PAULO. Ministério Público Estadual. GEVID. s/a. Disponível em: http:// www.mpsp.mp.br/portal/page/portal/GEVID. Acesso em: abr. 2020.

SÃO PAULO. Ministério Público Estadual. Mulher, vire a página... 2016. Disponível em: http://www.mpsp.mp.br/portal/page/portal/Cartilhas/ vire_a_pagina.pdf. Acesso em: 5 dez. 2019.

SCARDUELI, M. C. N.; MALISKA, M. E. Autonomia da mulher no discurso da violência: submissão mantida. PROLÍNGUA, v. 7, n. 1, p. 5-16, 12 jun. 2013. Disponível em: https://periodicos.ufpb.br/ojs2/index.php/prolingua/article/ view/16136. Acesso em: abr. 2020.

ZOPPI-FONTANA, M. G.; FERRARI, A. J. Apresentação: uma análise discursiva das identificações de gênero. In: ZOPPI-FONTANA, M. G; FERRARI, A.J. (Orgs.). Mulheres em discurso: identificações de gênero e práticas de resistência. 1. ed. Campinas, SP: Pontes, 2017. v. 2. 